\title{
Nomograms for Predicting Recurrent Herniation in PETD with Preoperative Radiological Factors
}

\author{
Chong Zhao (D* \\ Hao Zhang (D* \\ Yan Wang \\ Derong $\mathrm{Xu}$ \\ Shuo Han \\ Shengwei Meng (1D \\ Jialuo Han (D) \\ Houchen Liu \\ Chuanli Zhou \\ Xuexiao $\mathrm{Ma}$
}

Department of Spine Surgery, The Affiliated Hospital of Qingdao University, Qingdao, Shandong, People's Republic of China

*These authors contributed equally to this work

Correspondence: Xuexiao Ma; Chuanli

Zhou

Department of Spine Surgery, The Affiliated Hospital of Qingdao University, No.59 Haier Road, Qingdao, Shandong, 266000, People's Republic of China

Tel +86 I866I807895; +86 I866I809796

Email ma_xuexiao@।26.com; justin_

5257@hotmail.com
Purpose: To investigate the preoperative radiological risk factors for recurrent lumbar disc herniation ( $\mathrm{rLDH}$ ) within 1 year after percutaneous endoscopic transforaminal discectomy (PETD).

Patients and Methods: A retrospective case-control study was conducted. Between January 2013 and November 2019, a total of 1210 patients with single-level L4/5 LDH who underwent PETD were enrolled in the present study. In total, $62 \mathrm{rLDH}$ patients were diagnosed and collected based on the clinical and radiological manifestations, and 224 nonrLDH controls were selected from the remaining 1148 patients. Preoperative radiological parameters were collected and measured. An age threshold to distinguish patients into subgroups was established using the Youden index. The relationships between the risk factors and rLDH were evaluated by univariate and multivariate analyses in two subgroups. Predictive models were established based on logistic analysis. The area under the curve (AUC) of receiver operating characteristic (ROC) curves, calibration plots, and decision curve analysis (DCA) were used to assess the predictive models.

Results: In the present study, logistic analysis identified six significant predictors associated with rLDH in the young group: superior endplate concave angle (ECA), sacral slope, Modic changes, sagittal range of motion (sROM), extension intervertebral angle (IVA), and lumbar lordosis. Four significant predictors were identified in the elderly group: disc height index (DHI), retrolisthesis (posterior spondylolisthesis), sROM, and extension IVA. Validation of both models demonstrated excellent model discrimination (AUC $=0.940$ and 0.946 , respectively). DCA also showed excellent clinical utility and benefits.

Conclusion: The nomograms that we constructed could accurately predict individual patient recurrence risk. Individualized measures should be taken for patients of different ages with the above risk factors, and tailored postoperative surveillance of patients who underwent PETD can be planned.

Keywords: lumbar disc herniation, percutaneous endoscopic transforaminal discectomy, recurrent $\mathrm{LDH}$, risk factor

\section{Introduction}

Percutaneous endoscopic transforaminal lumbar discectomy (PETD) has become a routine surgery for lumbar disc herniation (LDH) because of its definite short-term curative effect, low trauma, and direct access to the focus. ${ }^{1,2}$ However, 5-20\% of patients do not experience a satisfactory curative effect after PETD. ${ }^{3,4}$ Recurrent lumbar disc herniation $(\mathrm{rLDH})$ is the most common but unpredictable reason for poor PETD outcomes, ${ }^{4-6}$ and the recurrence rate of PETD was reported to be 0 $12.5 \% .^{2}$ The definition of $\mathrm{rLDH}$ is a re-herniation of the same segment and ipsilateral intervertebral disc after a complete pain-free period of at least 2 weeks after PETD, causing the corresponding nerve root symptoms. $5,7,8$ 
In previous studies, several risk factors have been considered to be associated with $\mathrm{rLDH}$, such as advanced age, smoking, high body mass index (BMI) and waist trauma. ${ }^{7,9,10}$ In addition to the above clinically related factors, several special radiological factors caught our attention, which may affect the biomechanics and stability of the lumbar spine, thereby increasing the recurrence rate. Unique preoperative radiological characteristics may play an important role in the early prediction and prevention of rLDH, but these characteristics have not been systematically and holistically analyzed. Therefore, we performed a retrospective case-control study to sufficiently identify radiological risk factors associated with $\mathrm{rLDH}$ after PETD and to establish prognostic nomograms to predict rLDH risk, which provide detailed evidence-based data for preoperative evaluations and the selection of appropriate operation methods.

\section{Patients and Methods}

\section{Study Design}

Patients and Parameters

A retrospective case-control study was conducted. Between January 2013 and November 2019, a total of 1210 patients (675 male, 55.79\%; 535 female, 44.21\%) were reviewed. In total, 62 rLDH patients were identified and collected based on the clinical and radiological manifestations. The preoperative and postoperative imaging data and the endoscopic video data of all rLDH patients have been carefully studied and discussed within the medical team. Consensuses have been reached that the complete removal of the herniated nucleus has been achieved in the first operations. Considering the large number of non-recurrent patients and the huge internal variability among them, a propensity score matching (PSM) was performed to minimize the influence of selection bias and to control potential confounding factors. The PSM analysis matched three variables of sex, BMI, and preoperative symptom duration. Matching was performed using a 1:4 matching protocol (nearest-matching algorithm), with caliper width $=0.2$ of the standard deviation of the logit of the propensity score. A total of 224 nonrLDH controls were included in the control group (Figures 1 and 2). Radiological parameters (herniation type, Modic changes, Pfirrmann grade of disc degeneration, lumbosacral transitional vertebrae (LSTV), superior/ inferior endplate concave angle (ECA), lumbar lordosis, sacral slope, DHI, retrolisthesis (posterior spondylolisthesis), flexion/extension intervertebral angle (IVA), sROM, and upper/nether vertebral compression) were collected.

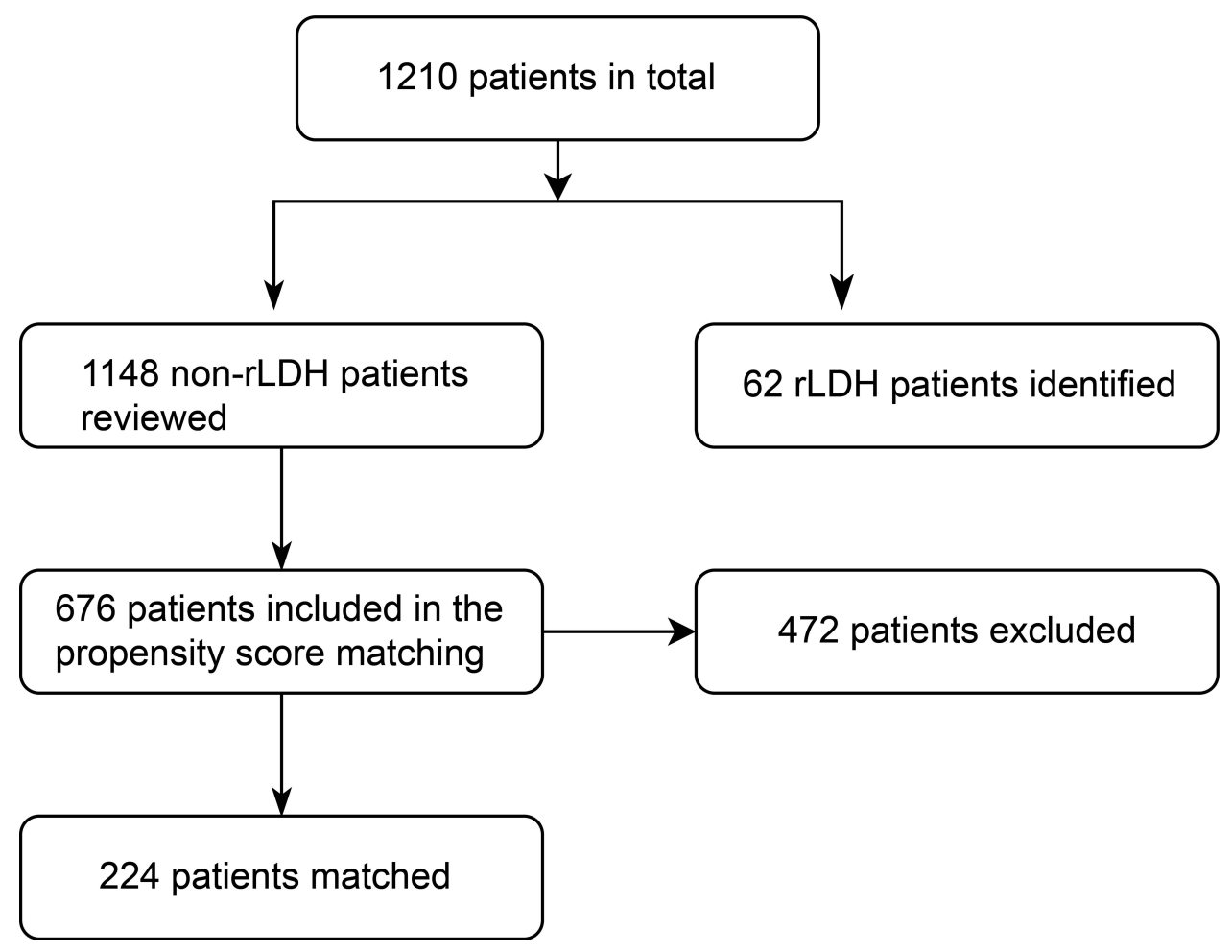

Figure I Flow chart of patient inclusion and exclusion. 


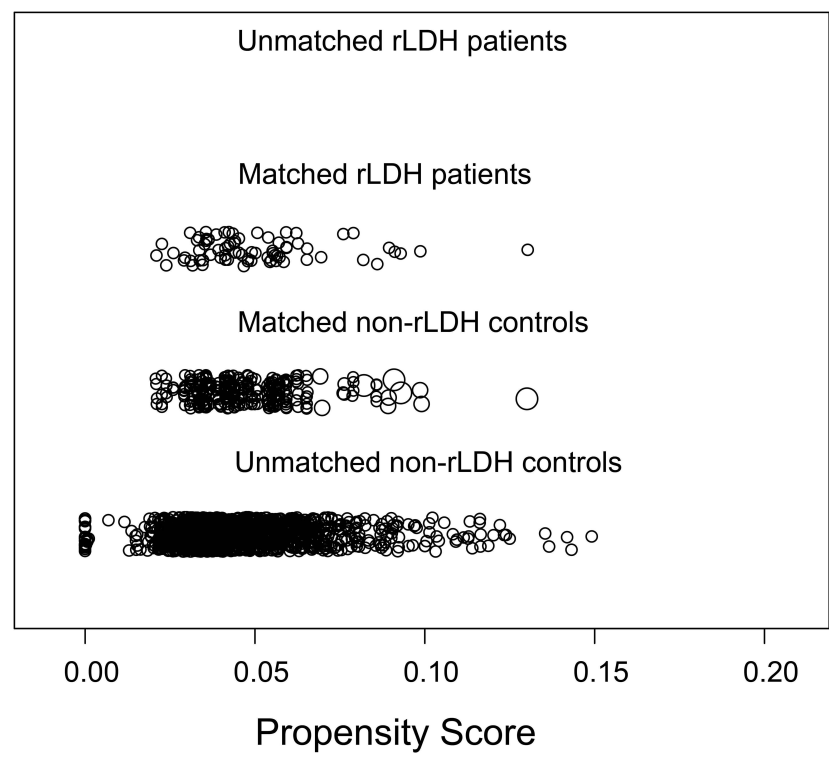

Figure 2 Distribution of propensity scores.

\section{Inclusion Criteria}

The inclusion criteria were as follows: 1) patients with single-level L4/5 LDH who underwent PETD and had postoperative images manifesting complete removal of the protruded disc; 2) patients who experienced a complete symptom-free interval of at least 2 weeks after PETD; 3) patients with ipsilateral re-protrusion of the same segment on MRI; and 4) patients who were regularly followed postoperatively for at least 1 year.

\section{Exclusion Criteria}

The exclusion criteria were as follows: 1) intermittent claudication and other obvious symptoms of spinal stenosis; 2) segmental instability; 3) multilevel LDH; 4) vertebral fractures; 5) spinal infection; 6) trauma; 7) tumors; and 8) previous lumbar surgery history.

No patients were lost to follow-up during the study period. All surgeries were performed by the same group of surgeons who had rich clinical surgery experience and were skillful in PETD operation technology. The procedures were approved by the ethics committee of the Affiliated Hospital of Qingdao University.

\section{Measurements of Radiological Features}

Lumbar magnetic resonance imaging (MRI), threedimensional computed tomography (CT) and X-ray, including flexion/extension posture, were performed for all patients before surgery. To eliminate bias, all radiographic parameters were analyzed and confirmed by a spine surgeon and a radiologist. Any disagreement in the grading was discussed until a consensus was achieved.

The Modic changes were classified into 3 types based on the T1/T2-weighted MRI sagittal sequence (Figure 3): type 1 (inflammatory phase) changes are hypointense on T1WI and hyperintense on T2WI; type 2 (fat phase or yellow bone marrow phase) changes are hyperintense on T1WI and hyper- or isointense on T2WI; and type 3 (osteosclerosis phase) changes are hypointense on T1WI and T2WI and are fairly rare. ${ }^{11}$

Herniation type was classified into 2 types (protrusion and extrusion) according to the Fardon classification. ${ }^{12}$ The degree of disc degeneration was assessed on T2WI sagittal sequences according to the modified Pfirrmann grade. Almost all patients suffered moderate to severe disc degeneration; hence, the degree of disc degeneration was classified into four levels (grades 3, 4, 5, and 6). Grades 1 and 2 were not observed in any patients.

LSTV was measured according to three-dimensional CT images of the lumbosacral area (Figure 4) and was classified into 4 types according to the Castellvi classification: ${ }^{13}$ type I, hypertrophy of transverse processes; type II, incomplete lumbarization/sacralization; type III, complete lumbarization/sacralization; and type IV, mixed findings. In the present study, types I and II were defined as low levels, while types III and IV were defined as high levels.

The flexion IVA, extension IVA, and sROM were measured on flexion/extension posture (Figure 5). IVA is defined as the angle between the upper and lower endplates, and sROM is defined as the difference between extension and flexion IVA. During the filming, the patients were asked to flex and extend as much as possible, and analgesics were used when necessary.

The ECA, namely, the endplate concave angle, is defined as the angle of the endplate concavity (Figure 6). If endplates are partially lacking due to the Schmorl nodes, the endplate arc should be completed according to the adjacent endplate. The superior and inferior ECAs were measured separately.

DHI and the vertebral compression index were measured on the sagittal reconstruction of three-dimensional CT (Figure 7), and the widths of the upper vertebral body (D) and the heights of the disc were measured. The heights of the disc were measured at the anterior (A), middle (B), and posterior $(\mathrm{C})$ edges of the intervertebral space. $\mathrm{DHI}=$ $(\mathrm{A}+\mathrm{B}+\mathrm{C}) /(3 * \mathrm{D})$. The vertebral compression index was calculated as the ratio of the average height to the width of the vertebrae. 

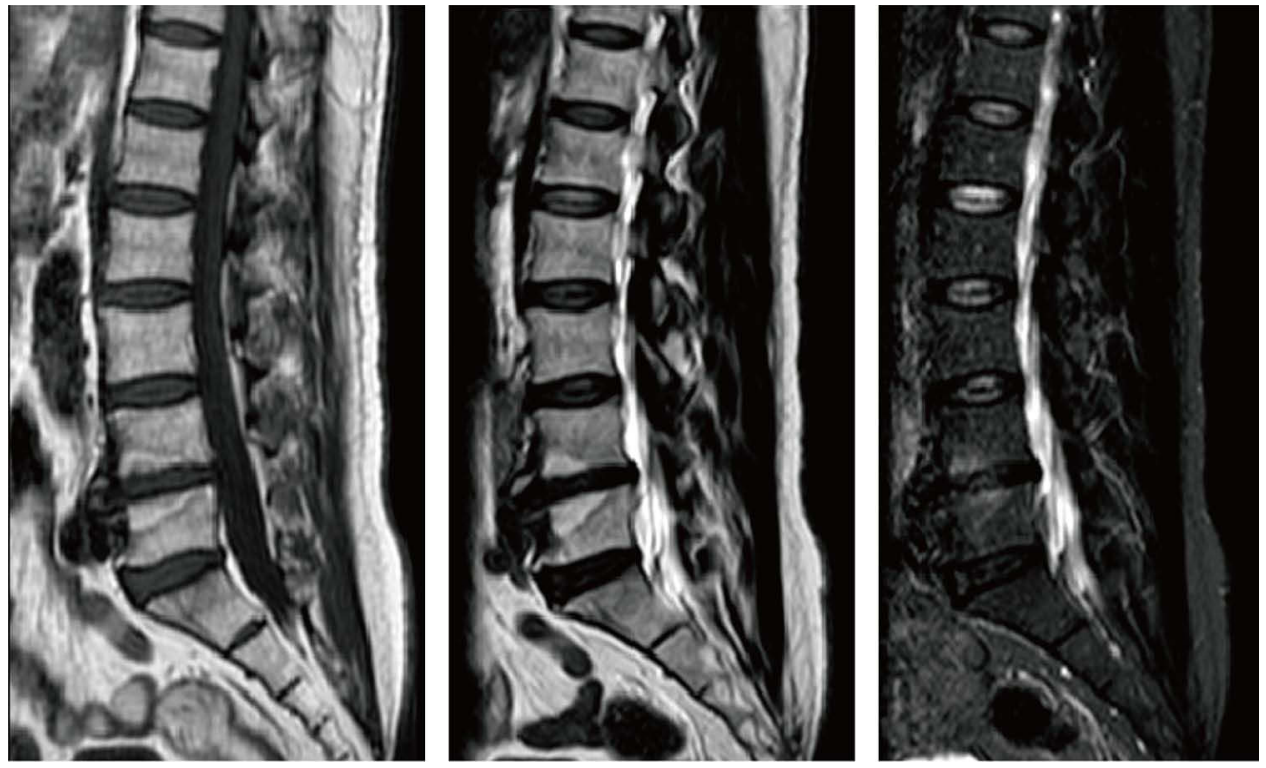

Figure $3 \mathrm{TIWI} / \mathrm{T} 2 \mathrm{WI} / \mathrm{STIR}$ sequences of preoperative sagittal MRI demonstrated Modic type 2.
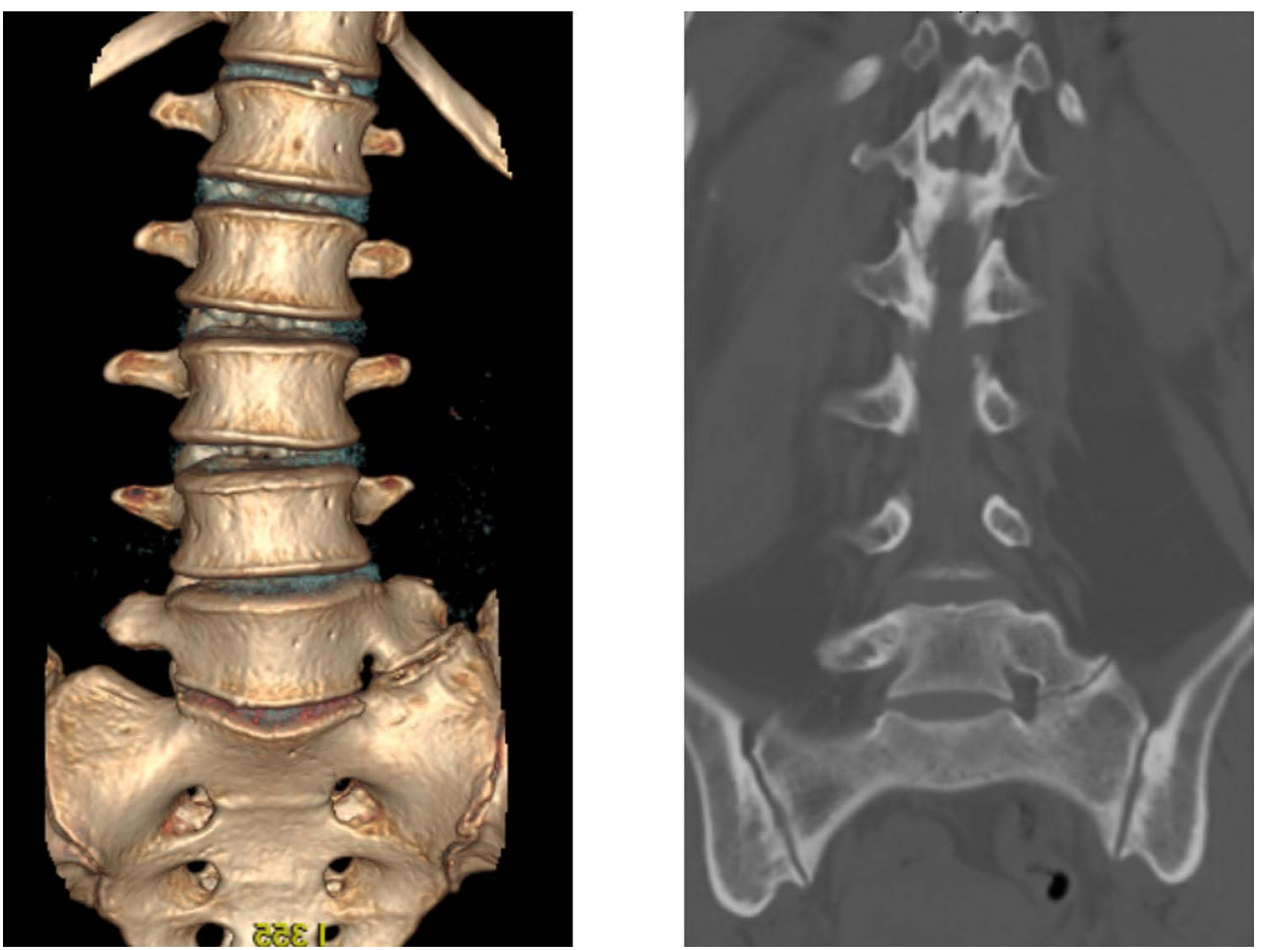

Figure 4 LSTV type II in 3-dimensional CT: unilateral incomplete lumbarization/sacralization.

Retrolisthesis is defined as backwards slippage of the upper vertebra. ${ }^{14}$ The retrolisthesis index was measured on the sagittal reconstruction of CT (Figure 8). The backward displacement distance of the upper vertebral body relative to the lower vertebral body (A) and the width of the upper vertebral body (B) were measured, and the retrolisthesis index was calculated as $\mathrm{A} / \mathrm{B}$.

\section{Statistical Analysis}

The Statistical Package for Social Sciences software for Windows (Ver. 26.0, SPSS Inc, Chicago, IL) and R 3.1.2 (The R Foundation for Statistical Computing, Vienna, Austria) were used for the analysis. The continuous data conformed to a normal distribution by the KolmogorovSmirnov test and were expressed as the mean \pm standard 


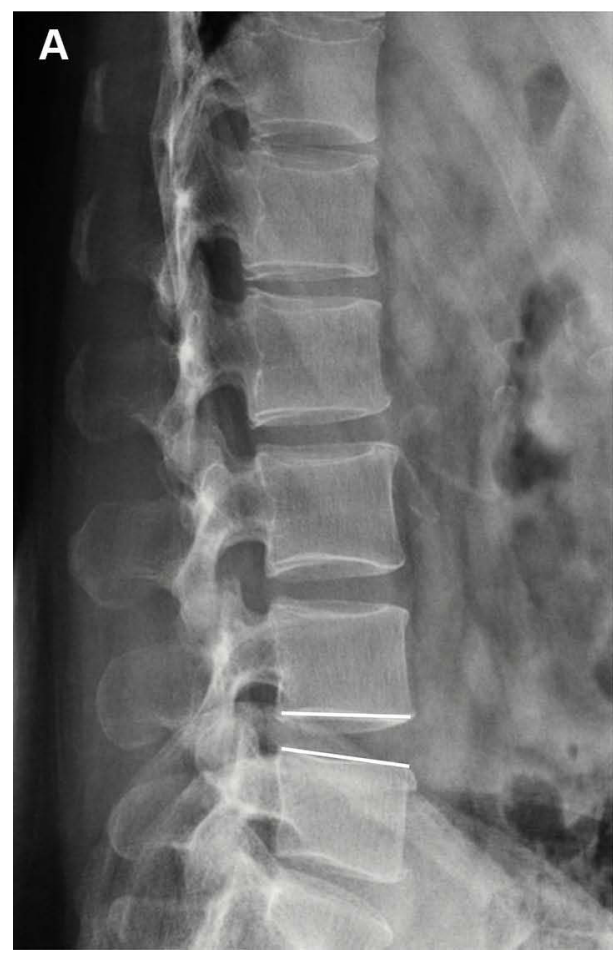

Figure 5 Measurement of the flexion IVA (A) and extension IVA (B).

deviation and tested with Student's $t$-test. Categorical data were tested with the chi-square or Fisher exact test, and ranked data were tested with Kendall's tau test. The variables with P-values less than 0.2 were further incorporated into the multivariable logistic regression analysis. A P-value $<0.05$ was considered statistically significant.

Subgroups were divided according to an age threshold determined by receiver operating characteristic (ROC) curve analysis. The cutoff value was determined by the Youden index. The predictive accuracy was evaluated by the AUC and calibration plot, and the model benefit was evaluated by the decision curve.

\section{Results}

\section{General Demographic and Radiological Data}

The non-rLDH $(\mathrm{n}=224)$ and $\mathrm{rLDH}(\mathrm{n}=62)$ groups were compared. There was no significant difference between the two groups in sex or BMI $(\mathrm{P}>0.05)$. The age of the $\mathrm{rLDH}$ group ranged from 23 to 79 years $(52.1 \pm 13.7$ years), and the mean age of the non-rLDH group was $44.9 \pm 14.0$ years, which was consistent with the overall patient population. The univariate analysis of baseline demographic and radiologic parameters is summarized in

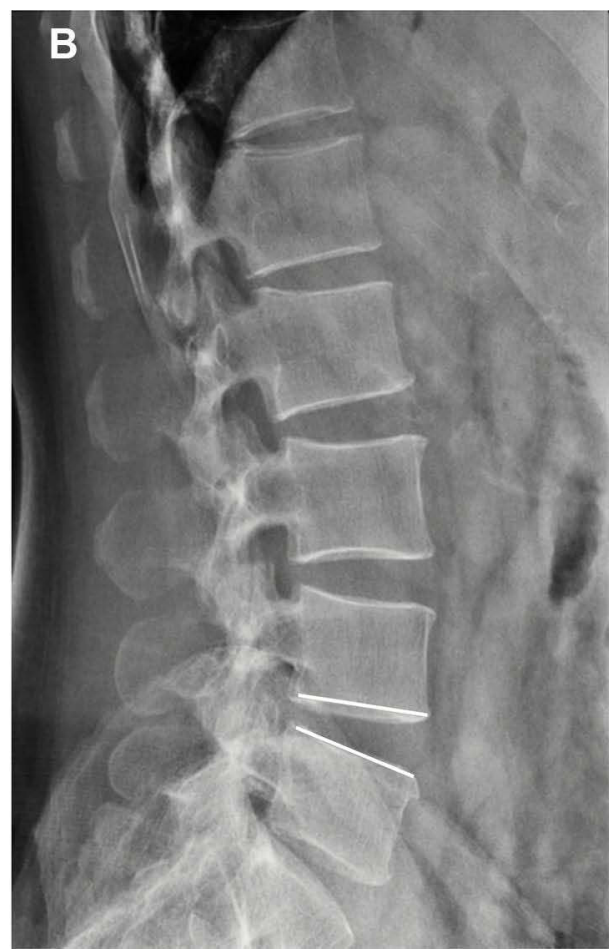

Table 1. Of these factors, age $(\mathrm{P}<0.001)$, herniation type ( $\mathrm{P}=0.037)$, Pfirrmann grade $(\mathrm{P}=0.022)$, LSTV $(\mathrm{P}=0.002)$, superior ECA $(\mathrm{P}<0.001)$, sacral slope $(\mathrm{P}<0.001)$, DHI $(\mathrm{P}=0.003), \quad$ retrolisthesis $\quad(\mathrm{P}<0.001)$, flexion IVA $(\mathrm{P}<0.001)$, extension IVA $(\mathrm{P}=0.007)$, and sROM $(\mathrm{P}<0.001)$ were found to be statistically significant with the incidence of rLDH.

Regarding treatment for the 62 patients with $\mathrm{rLDH}, 7$ patients received conservative treatment, 39 underwent revision PETD or percutaneous endoscopic interlaminar discectomy (PEID), and 16 underwent posterior lumbar fusion.

\section{Subgroup Analysis of Radiological Risk Factors}

Considering the significant age difference between rLDH and non-rLDH patients, a threshold to distinguish patients was established by the Youden index (Figure 9), and the age threshold was set at 50.5 years. Univariate and multivariate analyses were performed. The results indicated that a higher sROM and lower extension IVA increased the risk of rLDH for all ages. For the young group, superior ECA, Modic changes and lumbar lordosis were special factors for $\mathrm{rLDH}$, while retrolisthesis and DHI were special risk factors in the elderly group (Tables $2-5$ ). 


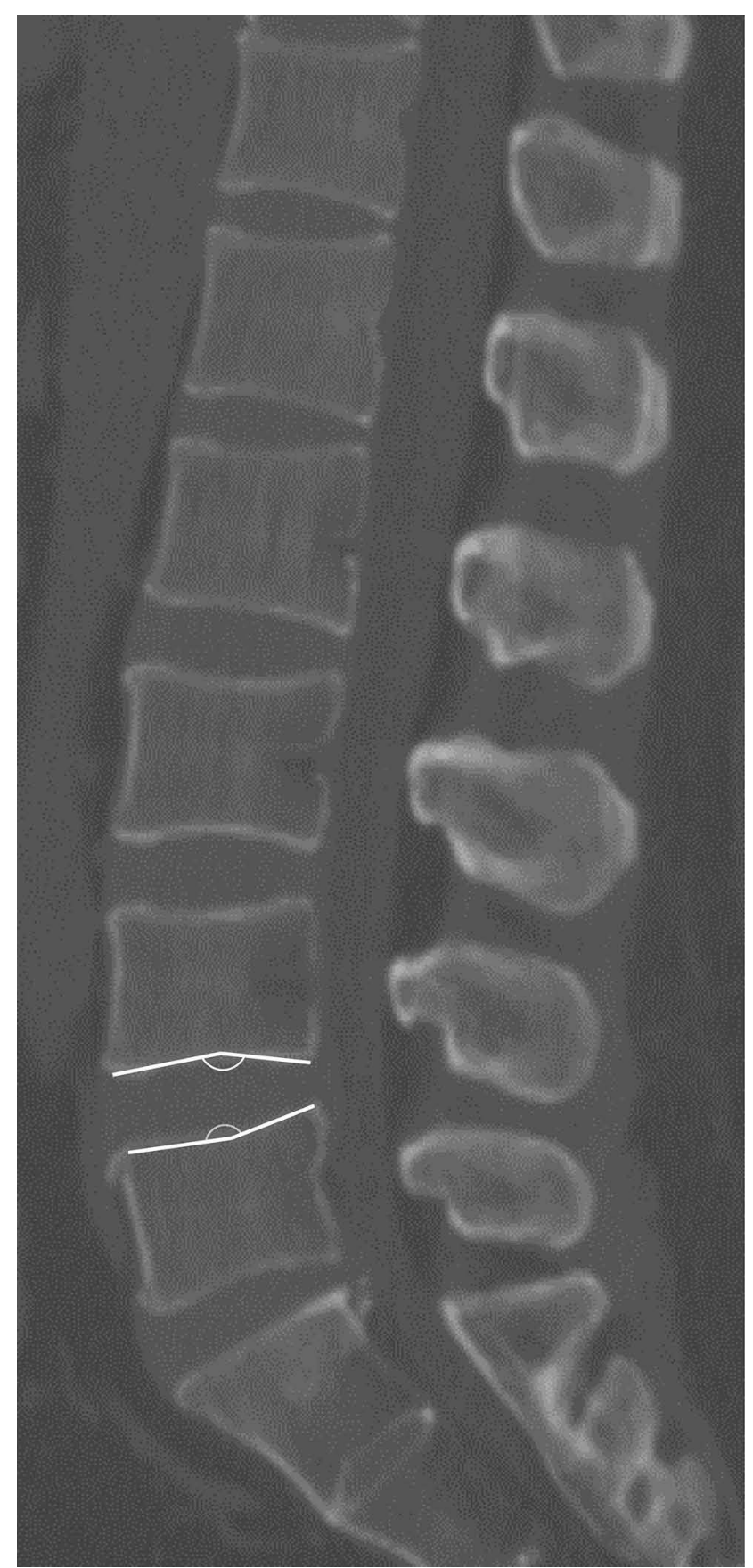

Figure 6 Measurement of the ECA: On the neutral sagittal T2WI, the bone endplate of vertebra is in arc shape. A line was drawn from the summit/bottom of arc along to the endpoints, and the angle between these 2 lines was defined as the ECA.

\section{Establishment and Evaluation of the Predictive Models}

Predictive models were established, and nomograms were built based on radiological factors selected by logistic regression (Tables 3 and 5; Figures 10 and 11). As a comparison, a logistic regression model for all ages was tried to established, and the AUC of this model was

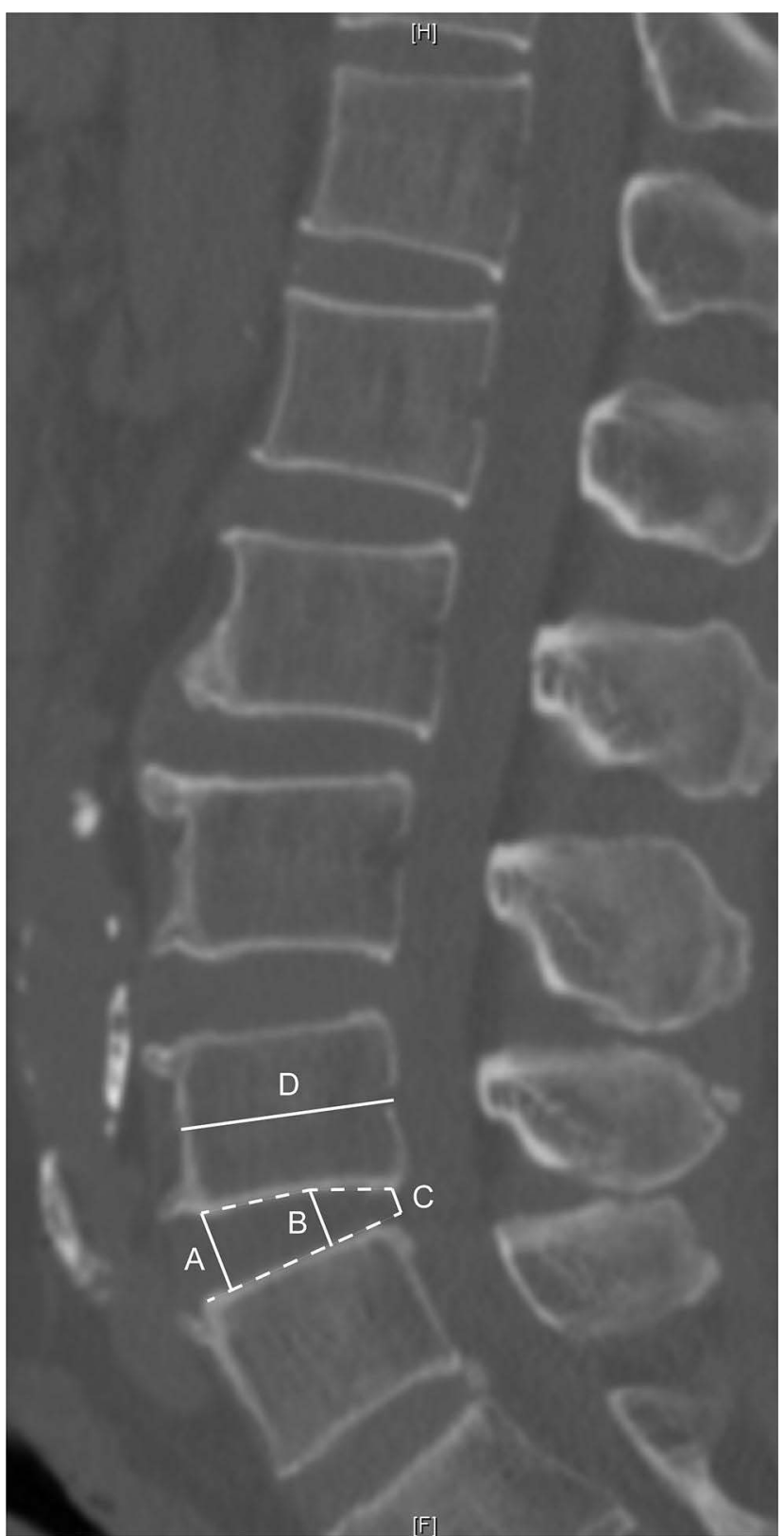

Figure 7 Measurement of the DHI: The height of the anterior (A), middle (B) and posterior $(C)$ intervertebral space and the width of the upper vertebral body (D) were measured. $\mathrm{DHI}=(A+B+C) /(3 * D)$.

0.895 (95\% CI: $0.846-0.943$ ), while that of the two subgroup models was 0.940 (95\% CI: $0.880-0.999)$ and 0.931 (95\% CI: 0.873-0.988), which showed the reasonability of subgroup analysis. The calibration plots indicated that the predicted probability and actual recurrence fit well (Figure 12), and the DCA curves showed that the models adjusted by subgroup analysis had better net benefits than the original model (Figure 13).

From December 2019 to December 2020, 13 rLDH patients and 50 non-rLDH patients were collected as the 


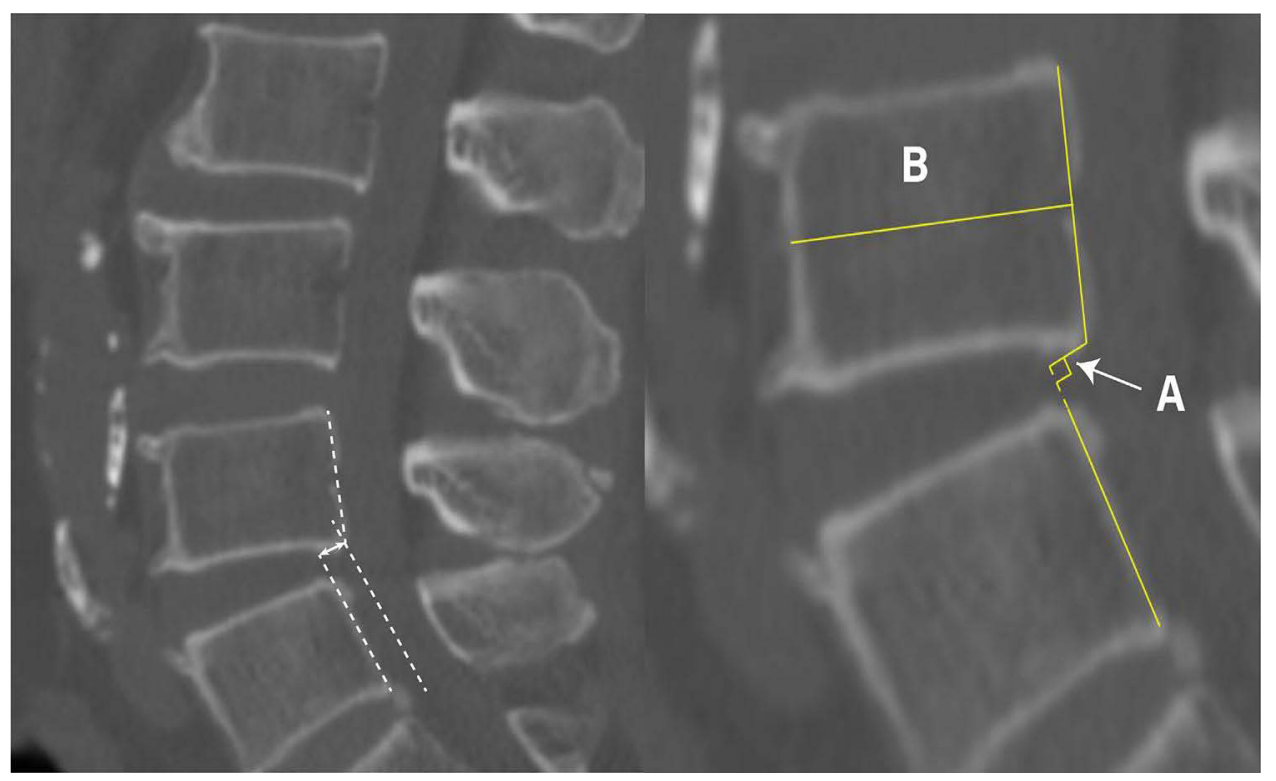

Figure 8 Measurement of the retrolisthesis index: The backward displacement distance of the upper vertebral body relative to the lower vertebral body (A) and the width of the upper vertebral body $(\mathbf{B})$ were measured. Retrolisthesis index $=\mathrm{A} / \mathrm{B}$.

testing cohort. Patients with a predicted recurrence probability greater than $50 \%$ were defined as high-risk patients. Overall, 77\% (10/13) of the patients in the rLDH group were assessed as high-risk patients, while in the non-rLDH group, this value was $38 \%(19 / 50)$. At the same time, all patients ( 6 cases) with a predicted recurrence probability greater than $80 \%$ suffered rLDH, which indicates the good predictive performance of the predictive models.

\section{Discussion}

This study aimed to explore the risk of each preoperative special radiological characteristic on the recurrence rate of patients who underwent PETD. Some factors, such as disc degeneration grade, DHI, and sROM, have been reported to be associated with rLDH. However, no consensus has been reached yet. We suspect that the differences were related to the age distribution of the subjects in these studies. When age increases, intervertebral disc degeneration occurs and is accompanied by hyperplasia of the intervertebral joint, spinal stenosis, and secondary potential instability. ${ }^{15-17}$ In addition, $\mathrm{Wu}$ et $\mathrm{al}^{18}$ proposed that advanced age ( $>40$ years) itself was a predisposing factor for rLDH. Therefore, PETD may be a compatible choice for young patients but has limitations for elderly patients.

\section{Retrolisthesis}

Spondylolisthesis is a common degenerative change and is generally defined as an anterior or posterior translation of a superior vertebra relative to a neighboring inferior vertebra in the sagittal plane. The incidence of spondylolisthesis in the middle-aged population reaches $17 \%$, of which retrolisthesis accounts for the majority. ${ }^{19}$ A series of studies have shown that retrolisthesis may be present in up to $30 \%$ of chronic low back pain patients. ${ }^{20}$ However, the systematic study of retrolisthesis is insufficient due to its special type and less incidence of lumbar spinal stenosis. Retrolisthesis may adversely affect the biomechanics of the disc and cause potential lumbar instability, thereby increasing the risk of $\mathrm{rLDH}$.

With the application of new tools such as largediameter endoscopes, reamers and ultrasonic osteotomes, the indication for PETD has been extended to a certain degree, and nearly complete decompression can be achieved, yet the stability of the local biomechanical structure may inevitably be weakened. Our results showed that the high rate of retrolisthesis in the elderly group had a significant effect on $\mathrm{rLDH}$, but no statistical significance was shown in the young group. There are two possible explanations. First, in the presence of retrolisthesis, the stress of the lumbar spine is concentrated toward the posterior edge of the disc, promoting the nucleus pulposus to protrude again. In addition, due to compensatory articular hypertrophy and spinal canal stenosis after retrolisthesis, it is unavoidable to remove a larger part of the upper articular process to obtain complete decompression, which is likely to cause iatrogenic segmental instability. 
Table I The Characteristics of Total Patients

\begin{tabular}{|c|c|c|c|}
\hline Factors & Non-Recurrent Group (n=224) & Recurrent Group $(n=62)$ & $P$ value \\
\hline \multicolumn{4}{|l|}{ Baseline demographics } \\
\hline Age (years) & $44.9 \pm 14.0$ & $52.1 \pm 13.7$ & $<0.001$ \\
\hline Sex (male: female) & 135: 89 & $37: 25$ & 0.933 \\
\hline BMI & $25.6 \pm 3.8$ & $26.0 \pm 4.4$ & 0.465 \\
\hline Preoperative duration (month) & $10.6 \pm 18.0$ & $16.8 \pm 47.4$ & 0.322 \\
\hline \multicolumn{4}{|l|}{ Radiologic parameters } \\
\hline Herniation type (protrusion: extrusion) & 152: 72 & 5I: II & 0.039 \\
\hline MODIC (0: I: 2: 3) & 146: 16: 62: 0 & 35: 5: $21: 1$ & 0.190 \\
\hline Pfirrmann grade $(3: 4: 5: 6)$ & 73: 88: $63: 0$ & 14: 23: 23: 2 & 0.032 \\
\hline LSTV (low: high) & 193: 31 & $4 I: 21$ & 0.001 \\
\hline Superior ECA (deg) & $161.5 \pm 8.0$ & $165.4 \pm 8.7$ & 0.001 \\
\hline Inferior ECA (deg) & $170.4 \pm 7.3$ & $170.2 \pm 8.6$ & 0.253 \\
\hline Lumbar lordosis angle (deg) & $37.3 \pm 10.9$ & $36.2 \pm 10.1$ & 0.495 \\
\hline Sacral slope angle (deg) & $28.2 \pm 6.4$ & $33.1 \pm 6.6$ & $<0.001$ \\
\hline $\mathrm{DHI}(\%)$ & $25.1 \pm 4.4$ & $27.4 \pm 5.2$ & 0.001 \\
\hline Retrolisthesis (0: I) & 217: 7 & 52: 10 & 0.001 \\
\hline Retrolisthesis index (\%) & $4.79 \pm 2.87$ & $8.12 \pm 4.46$ & $<0.001$ \\
\hline Flexion endplate angle (deg) & $6.02 \pm 3.75$ & $2.33 \pm 5.54$ & $<0.001$ \\
\hline Extension endplate angle (deg) & $1 \mathrm{I} .24 \pm 4.49$ & $8.82 \pm 6.64$ & 0.001 \\
\hline sROM (deg) & $4.76 \pm 3.14$ & $7.25 \pm 4.00$ & $<0.001$ \\
\hline Upper vertebral compression (\%) & $2.28 \pm 0.22$ & $2.24 \pm 0.28$ & 0.338 \\
\hline Nether vertebral compression (\%) & $2.18 \pm 0.20$ & $2.19 \pm 0.20$ & 0.804 \\
\hline
\end{tabular}

However, for LDH patients with stable retrolisthesis and contraindications to lumbar fusion, PETD surgery may have a higher recurrence rate, but it still has prominent advantages over traditional open surgery.

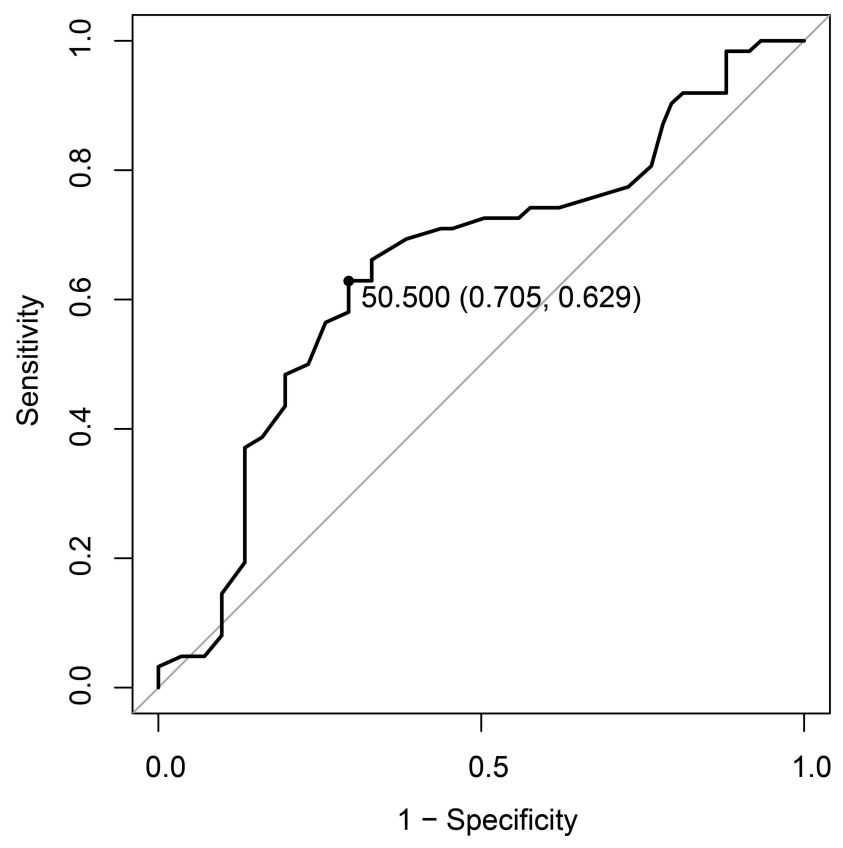

Figure 9 Optimal threshold point of age ROC curve.
This fact requires surgeons to formulate a personalized plan before operations, such as minimizing the destruction of the articular process and placing the working channels horizontally and close to the center line to the greatest extent to thoroughly deal with the intervertebral space.

\section{sROM and Extension IVA}

SROM is considered a risk factor for $\mathrm{rLDH}$ because it may cause intervertebral space instability. ${ }^{10}$ Kim et $\mathrm{al}^{10}$ reported that the postoperative recurrence rate was only $4.1 \%$ when $\mathrm{sROM}<10^{\circ}$, and the postoperative recurrence rate was as high as $26.5 \%$ when $\mathrm{sROM}>10^{\circ}$, which suggested a strong association between high sROM and rLDH. In the present study, sROM and extension IVA were both independent risk factors for rLDH in both subgroups. ROC analysis (Figure 14) suggested that for the young group, sROM contributed more to the predictive ability of the model than that for the elderly group. This result may be explained by the degeneration of the lumbar curvature and the hypertrophy of the articular processes in the elderly group, which contribute to reduce the relative intervertebral mobility; as a result, the impact of sROM on rLDH was less important. 
Table 2 The Characteristics of Patients in the Young Group

\begin{tabular}{|l|l|l|l|}
\hline Factors & Non-Recurrent Group (n=1 58) & Recurrent Group (n=23) & P value \\
\hline Sex (male: female) & $89: 69$ & II: 12 & 0.444 \\
BMI & $25.58 \pm 4.24$ & $25.24 \pm 4.40$ & 0.723 \\
Preoperative duration (month) & $10.19 \pm 17.60$ & $13.87 \pm 36.64$ & 0.430 \\
Herniation type (protrusion: extrusion) & $110: 48$ & $20: 3$ & 0.134 \\
Modic (0: I: 2: 3) & $110: 4: 44: 0$ & $11: 2: 9: 1$ & 0.009 \\
Pfirrmann grade (3: 4: 5: 6) & $59: 56: 43: 0$ & $4: 6: 12: 1$ & 0.008 \\
LSTV (low: high) & $141: 17$ & $15: 8$ & $165.89 \pm 9.63$ \\
Superior ECA (deg) & $160.06 \pm 8.23$ & $172.41 \pm 7.62$ & 0.005 \\
Inferior ECA (deg) & $170.44 \pm 7.47$ & $31.77 \pm 9.86$ & 0.002 \\
Lumbar lordosis (deg) & $35.53 \pm 10.94$ & $32.00 \pm 5.62$ & 0.380 \\
Sacral slope (deg) & $27.31 \pm 6.16$ & $25.76 \pm 4.23$ & 0.121 \\
DHI (\%) & $25.81 \pm 4.32$ & $21: 2$ & 0.001 \\
Retrolisthesis (0: I) & $152: 6$ & $6.13 \pm 4.30$ & 0.957 \\
Retrolisthesis index (\%) & $4.81 \pm 2.85$ & $-0.40 \pm 5.88$ & 0.269 \\
Flexion intervertebral angle (deg) & $5.28 \pm 3.65$ & $5.06 \pm 8.32$ & \\
Extension intervertebral angle (deg) & $10.23 \pm 4.29$ & $6.82 \pm 3.72$ & \\
sROM (deg) & $4.55 \pm 3.24$ & $2.36 \pm 0.21$ & \\
Upper vertebral compression (\%) & $2.32 \pm 0.22$ & $2.28 \pm 0.14$ & \\
Nether vertebral compression (\%) & $2.20 \pm 0.19$ & & \\
\hline
\end{tabular}

Table 3 The Logistic Analysis of Patients in the Young Group

\begin{tabular}{|c|c|c|c|}
\hline Factors & OR (95\% CI) & $P$ value & Significance \\
\hline Superior ECA & $1.121(1.013-1.241)$ & 0.027 & $*$ \\
\hline Sacral slope & $1.262(1.061-1.501)$ & 0.008 & $* *$ \\
\hline $\begin{array}{l}\text { Modic change } \\
\text { None } \\
\text { Modic II }\end{array}$ & $\begin{array}{l}\text { I } \\
\text { |4.270 (1.882-108.206) }\end{array}$ & 0.010 & $*$ \\
\hline $\begin{array}{l}\text { sROM } \\
\text { Extension IVA } \\
\text { Lumbar lordosis }\end{array}$ & $\begin{array}{l}2.200(1.443-3.353) \\
0.722(0.586-0.890) \\
0.846(0.744-0.963)\end{array}$ & $\begin{array}{l}<0.001 \\
0.002 \\
0.011\end{array}$ & $\begin{array}{l}* * * \\
* * \\
*\end{array}$ \\
\hline
\end{tabular}

Note: $* \mathrm{P}<0.05, * * \mathrm{P}<0.01, * * * \mathrm{P}<0.001$.

In addition, we noticed that in all 21 patients with NFIVA (negative flexion intervertebral angle, flexion intervertebral angle $\leq 0$, Figure 15), 17 had $\mathrm{rLDH}$ $(81.0 \%)$. In the subgroup analysis, 4 in 15 with NFIVA (26.7\%) had rLDH in the young group, and 6 in 6 with NFIVA $(100 \%)$ had $\mathrm{rLDH}$ in the elderly group, suggesting that NFIVA, or segmental kyphosis, of the intervertebral space could be a strong risk factor for rLDH, particularly in elderly individuals. Given this result, we recommend that for elderly patients with preoperative NFIVA, PETD surgery must be performed with great caution, while the postoperative recovery period should be relatively extended to minimize the possibility of recurrence.

\section{Endplate Concave Angle (ECA)}

The vertebral endplate is composed of trabecular bone layers, which provide nutrition to intervertebral discs and undertake pressure from above. A series of studies have suggested a correlation between morphological changes in endplates and lumbar disc degeneration. ${ }^{21,22}$ As the degeneration of the intervertebral disc worsens, the axial stress on the endplate of the vertebral body gradually shifts from the central area to the periphery, leading to the absorption and remodeling of the surrounding endplate, which in turn compresses the periphery of the vertebral body and causes the endplate to become flatter; hence, the axial stress is dispersed. In this way, the degree of endplate concavity significantly affects the axial stress exerted on the intervertebral disc. ${ }^{21}$ Therefore, the flattening of the endplate may be a self-protective mechanism, and ECA may be a sensitive factor reflecting the degree of intervertebral disc degeneration to a certain extent.

In the present study, superior ECA was identified as an independent risk factor in the young group, but no statistical significance was shown in the elderly group. We hypothesize that because of the generally severe degeneration of intervertebral discs in the elderly group, which exceeded the compensatory effect of ECA, the intragroup difference in ECA in the elderly group was statistically insignificant. In particular, in the young group, the mean value of superior ECA $(165.89 \pm 9.63)$ of rLDH patients 
Table 4 The Characteristics of Patients in the Old Group

\begin{tabular}{|l|l|l|l|}
\hline Factors & Non-Recurrent Group (n=66) & Recurrent Group (n=39) & P value \\
\hline Sex (male: female) & $30: 36$ & $21: 18$ & 0.406 \\
BMI & $24.76 \pm 2.99$ & $25.63 \pm 3.12$ & 0.160 \\
Preoperative duration (month) & $11.73 \pm 19.02$ & $18.47 \pm 53.08$ & 0.350 \\
Herniation type (protrusion: extrusion) & $42: 24$ & $31: 8$ & 0.124 \\
Modic (0: I: 2: 3) & $36: 12: 18: 0$ & $24: 3: 12: 0$ & 0.739 \\
Pfirrmann grade (3: 4: 5: 6) & $14: 32: 20: 0$ & $10: 17: 11: 1$ & 0.860 \\
LSTV (low: high) & $52: 14$ & $26: 13$ & 0.248 \\
Superior ECA (deg) & $164.83 \pm 6.27$ & $165.17 \pm 8.24$ & 0.814 \\
Inferior ECA (deg) & $170.30 \pm 6.79$ & $168.96 \pm 8.93$ & 0.699 \\
Lumbar lordosis (deg) & $41.47 \pm 9.63$ & $38.86 \pm 9.36$ & 0.179 \\
Sacral slope (deg) & $30.18 \pm 6.60$ & $33.82 \pm 7.10$ & 0.009 \\
DHI (\%) & $23.55 \pm 4.17$ & $28.38 \pm 5.54$ & $<0.001$ \\
Retrolisthesis (0: I) & $65: 1$ & $31: 8$ & 0.001 \\
Retrolisthesis index (\%) & $4.76 \pm 2.92$ & $9.29 \pm 4.18$ & $<0.001$ \\
Flexion intervertebral angle (deg) & $7.79 \pm 3.41$ & $3.94 \pm 4.69$ & \\
Extension intervertebral angle (deg) & $13.65 \pm 4.04$ & $11.03 \pm 4.13$ & \\
sROM (deg) & $5.28 \pm 2.84$ & $7.51 \pm 4.18$ & \\
\hline
\end{tabular}

Table 5 The Logistic Analysis of Patients in the Old Group

\begin{tabular}{|l|l|l|l|}
\hline Factors & OR (95\% Cl) & P value & Significance \\
\hline DHI & I.344 (I.139-I.586) & $<0.001$ & $*$ \\
\hline $\begin{array}{l}\text { Retrolisthesis } \\
\text { None } \\
\text { Retrolisthesis }\end{array}$ & I II.226 (I.012-124.559) & 0.049 & $*$ \\
\hline $\begin{array}{l}\text { sROM } \\
\text { Extension IVA }\end{array}$ & $\begin{array}{l}\text { I.677 (I.297-2.168) } \\
0.651(0.542-0.783)\end{array}$ & $\begin{array}{l}<0.0001 \\
<0.0001\end{array}$ & $* * * *$ \\
\hline
\end{tabular}

Note: $* \mathrm{P}<0.05,{ }^{*} * * \mathrm{P}<0.001$.

was much higher than that of non-rLDH patients $(160.06 \pm$ $8.23)$ but was close to that in the whole elderly group (164.96 \pm 7.03$)$, which supported our hypothesis.

\section{Herniation Type}

Depending on the amount of disc herniation, herniated discs can be classified as protrusions or extrusions according to Fardon's classification. Generally, due to the small working space of the operation, the narrow field of vision, and the blind zones around the working channel, ${ }^{23}$ the treatment of the protrusion type is not as thorough as that of the extrusion type; hence, the protrusion type of herniation may be a risk factor for rLDH. Studies by Kim et $\mathrm{al}^{24}$ reported that the recurrence rate of minimally invasive surgery for LDH whose pathological type was protrusion reached $15.9 \%$, while the postoperative recurrence rate of extrusion was $3.7 \%$. However, in the present study, herniation type was not a risk factor for rLDH in the two subgroups. With the application of new tools such as large outer-diameter working channels, the surgical area can be fully exposed, the protrusion can be almost completely removed, and the intervertebral space can be fully treated, which significantly reduces the recurrence rate. This may be the reason why the protrusion type of herniation was not a significant risk factor in our research.

\section{Modic Changes}

In previous studies, ${ }^{24-27}$ preoperative Modic change suggested a trend toward a negative correlation with clinical improvement in patients undergoing PETD. In the present study, a significant relationship between disc degeneration grade and Modic changes was found $(\mathrm{P}=0.003)$, suggesting that Modic changes may accelerate disc degeneration. At the same time, there was a strong correlation between Modic changes and rLDH in the young group, but there was no significant correlation in the elderly group, suggesting that Modic changes had a greater impact on the less degenerated intervertebral discs. A possible explanation is that Modic changes reflect a reactive vertebral modification related to disc inflammation and an unstable microenvironment, which affects the less degenerated intervertebral discs more, thus leading to a higher risk of rLDH. For elderly patients, due to the hyperostosis and marginal sclerosis of intervertebral discs, local inflammation is no longer an important factor in $\mathrm{rLDH}$; thus, Modic changes have no effect on rLDH. 
Points

$\begin{array}{lllllllllll}0 & 10 & 20 & 30 & 40 & 50 & 60 & 70 & 80 & 90 & 100\end{array}$

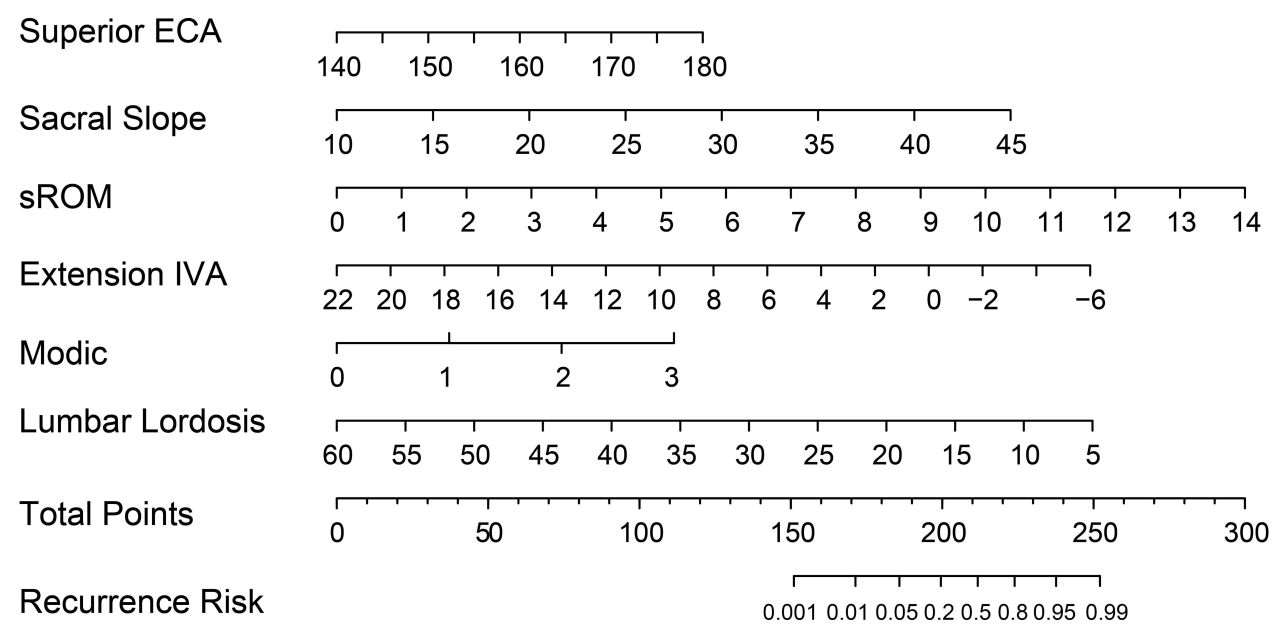

Figure 10 Nomogram for predicting recurrence risk in the young group (age $<50.5$ years).

Points

$\begin{array}{lllllllllll}0 & 10 & 20 & 30 & 40 & 50 & 60 & 70 & 80 & 90 & 100\end{array}$

$\mathrm{DHI}$

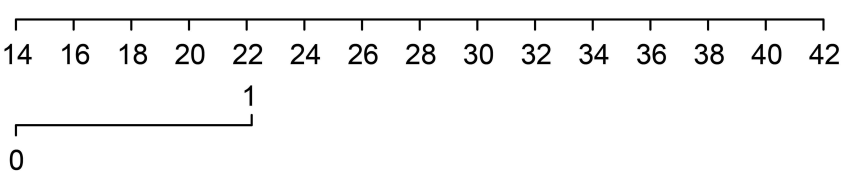

sROM

\begin{tabular}{|c|c|c|c|c|c|c|c|c|}
\hline$T$ & T & $T$ & $T$ & $T$ & $T$ & $T$ & & \\
\hline 2 & 4 & 6 & 8 & 10 & 12 & 14 & 16 & 18 \\
\hline
\end{tabular}

ExtensionIVA

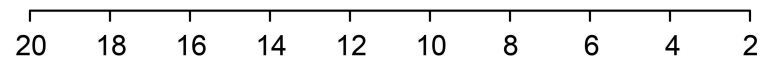

Total Points

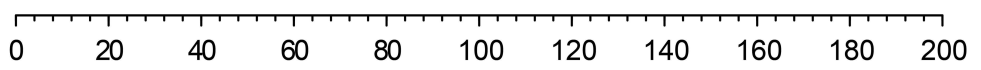

Recurrence Risk

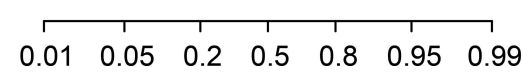

Figure I I Nomogram for predicting recurrence risk in the old group (age > 50.5 years).

\section{$\mathrm{DHI}$}

DHI is considered related to the degeneration of the intervertebral disc and the stability of the lumbar spine, which affects the development of rLDH. ${ }^{10,28,29}$ When the intervertebral disc is severely degenerated, the intervertebral space collapses, resulting in a decrease in intervertebral motion, which may lead to local stabilization of the intervertebral space and reduce the risk of rLDH. Hasegawa et $\mathrm{al}^{29}$ reported that degenerated segments that retain the height of the intervertebral disc were potentially unstable compared to segments with collapsed intervertebral discs.
In the present study, the recurrence rate of patients with high DHI in the elderly group was significantly higher, but this was not seen in the young group. This result may be explained by the relatively fine condition of the intervertebral discs in the young group. Kirkaldy-Willis and Farfan ${ }^{28}$ proposed the concept of disc degeneration progression, which includes three stages: dysfunction, instability and restabilization. For young patients, the degeneration of the intervertebral disc is less severe and has not yet reached a level that significantly affects the disc height; therefore, the disc height is generally 

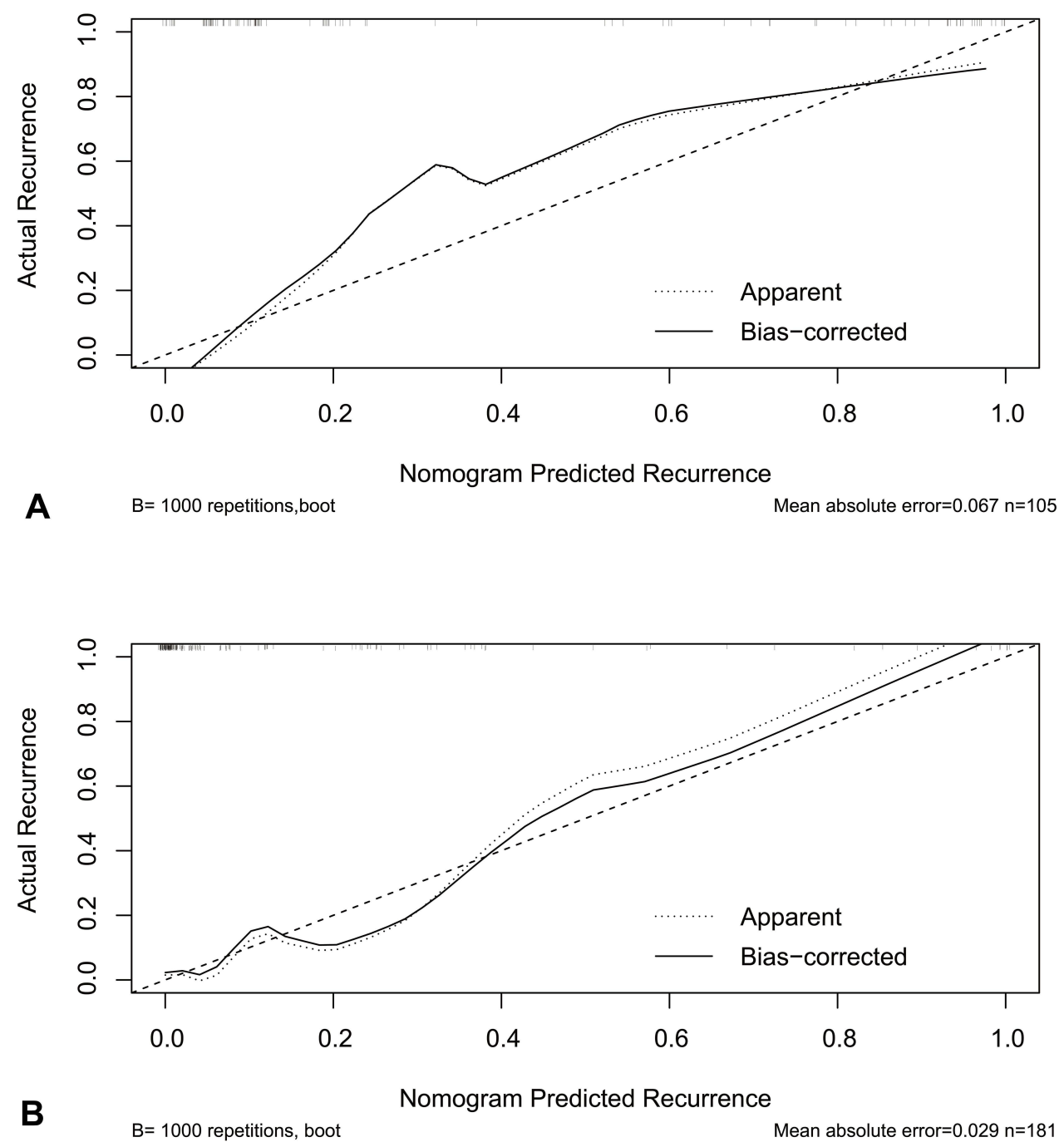

Figure 12 Calibration curve of the young group model (A) and the old group model (B).

preserved. There was no instability-restabilization process in the intervertebral spaces of young patients. Therefore, DHI was not a significant risk factor for young patients.

\section{Lumbosacral Transitional Vertebrae (LSTV)}

LSTV is a spinal deformity referring to a total or partial unilateral or bilateral fusion of the transverse process of the lowest lumbar vertebra to the sacrum, ${ }^{13}$ which is common in the general population. Several studies have suggested that LSTV has a significant effect on lumbar disc herniation in adolescents by changing the anatomical structure and biomechanical conduction of the lumbosacral region. $^{30,31}$ Although still uncertain, the presence of an LSTV may accelerate disc degeneration because the contact between the transverse process and the sacrum may compensatively lead to a larger range of motion of the segment above the LSTV, increasing the stress of the intervertebral discs and the instability of the lumbar segment, which leads to $\mathrm{rLDH} .{ }^{31}$ However, in the present study, the presence of an LSTV was not an independent risk factor in either subgroup. The relationship between LSTV and rLDH may be more complicated and needs further research.

\section{Predictive Models and Nomograms}

In this study, we established predictive models according to subgroup analysis. In the young group, Modic changes had a significant impact, while DHI and retrolisthesis showed little influence, in contrast to the findings in the elderly group. These findings indicated that for young patients, the inflammatory reaction of the intervertebral space and disorder of the local 


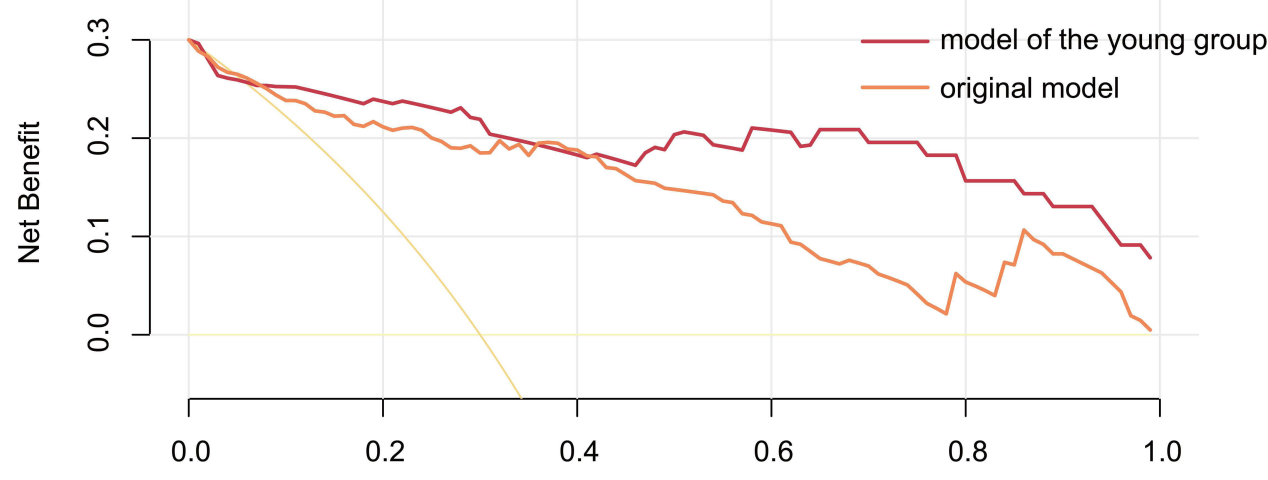

A

High Risk Threshold

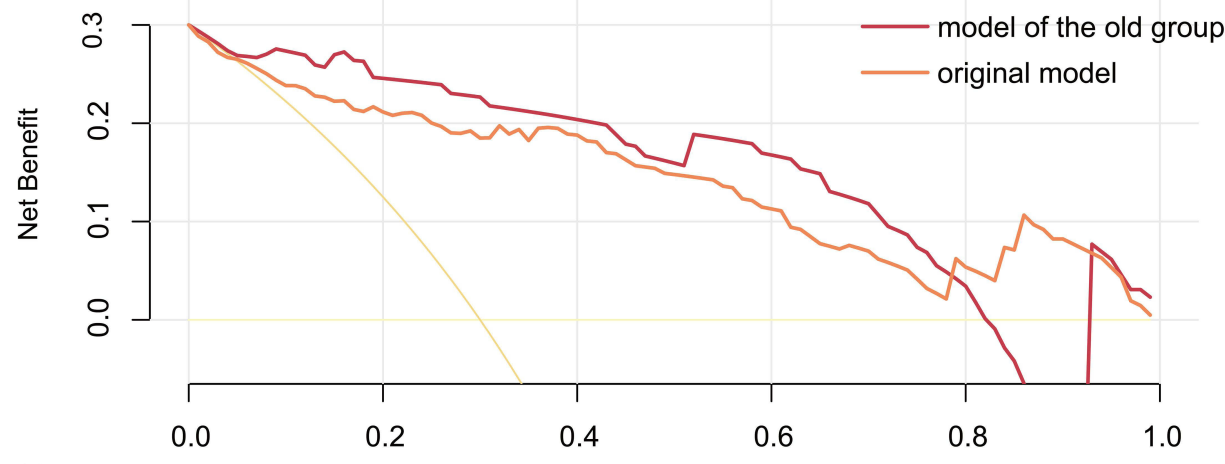

B

High Risk Threshold

Figure 13 Decision curve of the young group model (A) and the old group model (B).

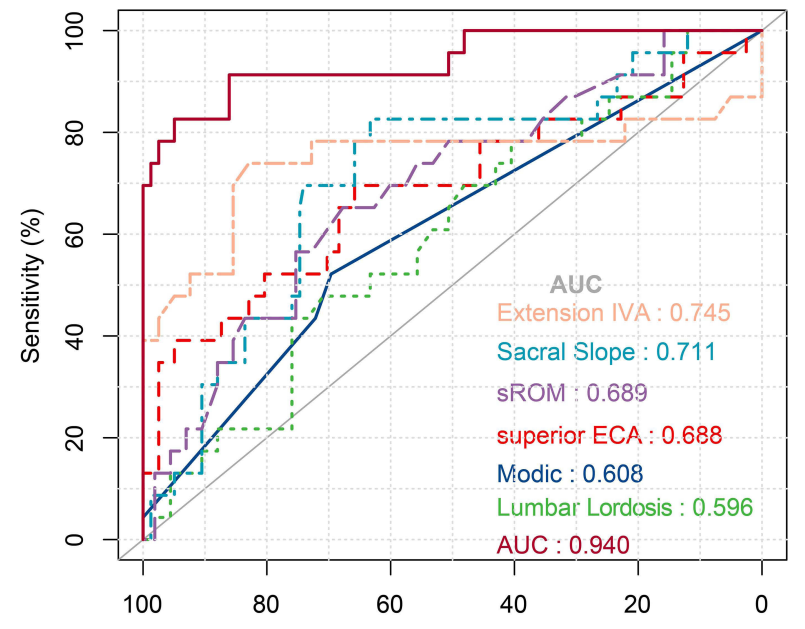

A

Specificity (\%)

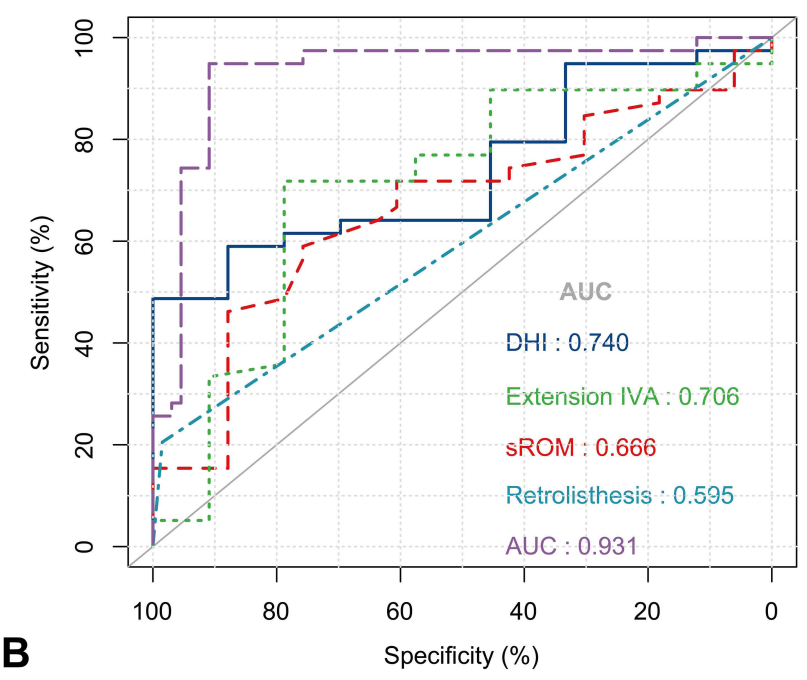

Figure 14 ROC curves of the predictive models (A) young group; (B) old group).

microenvironment could be the primary threat leading to $\mathrm{rLDH}$, and for elderly patients, height preservation of the lumbar spine or biomechanical changes of the intervertebral space could increase the risk of rLDH. Judging from the performance of SROM and the extension of the intervertebral angle in both models, the increased mobility of the lumbar spine posed a threat to the surgical effect at all ages. 


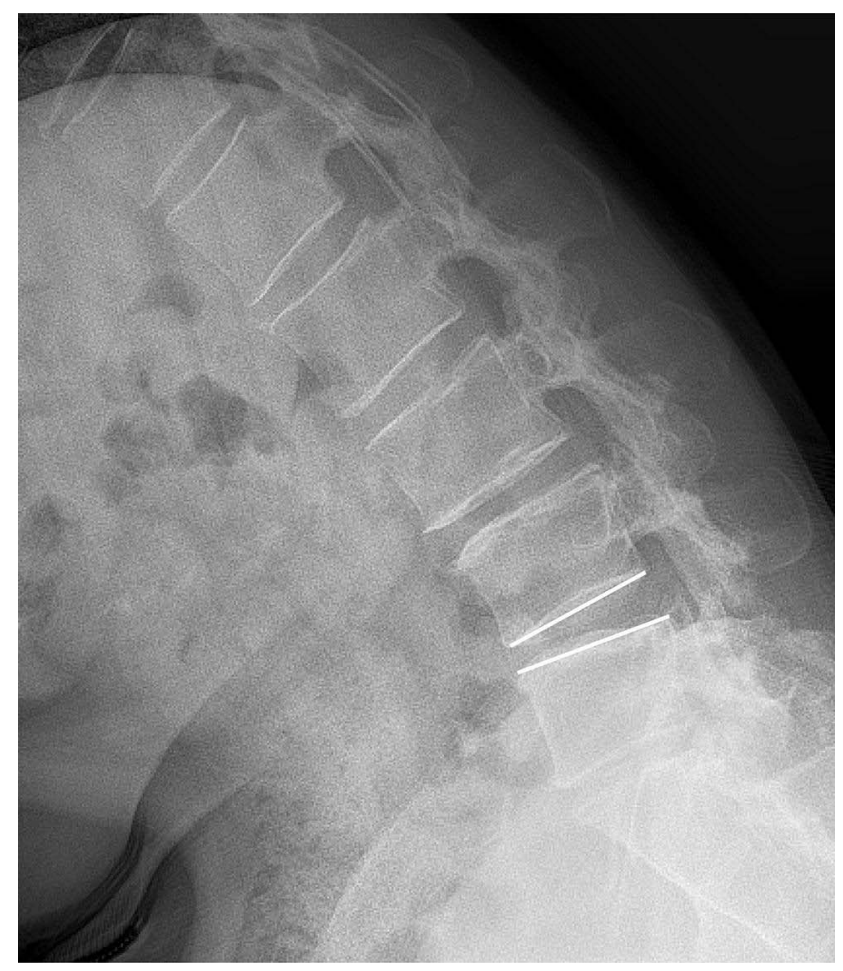

Figure I5 Negative flexion intervertebral angle.

\section{Limitations of the Study}

This study had several limitations. As a retrospective nonrandomized case-control study, the number of positive individuals was relatively small, and the radiological data were measured manually by researchers, with an unavoidable subjective bias. In addition, the postoperative follow-up time was relatively short in this study, and the long-term recurrence rate remains to be studied further. Therefore, a larger population would be better to modify and validate the predictive model. Future studies, especially randomized controlled trials, are needed to verify the results.

\section{Conclusions}

This is the first study to develop a screening tool to identify patients at risk for rLDH after PETD. With further validation, this tool can be readily implemented in clinical practice, and tailored postoperative surveillance of patients who underwent PETD can be planned.

\section{Ethics Approval and Consent to Participate}

This study was approved by the ethics committee of the Affiliated Hospital of Qingdao University. Written informed consent was obtained from all participants.
Meanwhile, all personal details were erased before analysis to cover patient data and comply with the Declaration of Helsinki.

\section{Consent for Publication}

All authors have confirmed that the content can be published, and agreed to submit it for consideration for publication in the journal.

\section{Acknowledgments}

Special thanks go to all staff of the Orthopedic Medical Center of the Affiliated Hospital of Qingdao University for their support and selfless dedication. Chong Zhao and Hao Zhang contributed equally to this work. Xuexiao Ma and Chuanli Zhou should be both considered as the corresponding authors.

\section{Funding}

This work was supported by grants from the National Natural Science Foundation of China (81672200 and 81871804) and the National Key Research and Development Project (CN) (2019YFC0121400).

\section{Disclosure}

The authors report no conflicts of interest in this work.

\section{References}

1. Yeung AT. The evolution of percutaneous spinal endoscopy and discectomy: state of the art. Mt Sinai J Med. 2000;67(4):327-332.

2. Choi K-C, Lee J-H, Kim J-S, et al. Unsuccessful percutaneous endoscopic lumbar discectomy: a single-center experience of 10,228 cases. Neurosurgery. 2015;76(4):372-380; discussion 380-381; quiz 381. doi:10.1227/NEU.0000000000000628

3. Carragee EJ, Han MY, Suen PW, Kim D. Clinical outcomes after lumbar discectomy for sciatica: the effects of fragment type and anular competence. J Bone Joint Surg Am. 2003;85(1):102-108. doi:10.2106/ 00004623-200301000-00016

4. Aizawa T, Ozawa H, Kusakabe T, et al. Reoperation for recurrent lumbar disc herniation: a study over a 20-year period in a Japanese population. J Orthop Sci. 2012;17(2):107-113. doi:10.1007/s00776011-0184-6

5. Swartz KR, Trost GR. Recurrent lumbar disc herniation. Neurosurg Focus. 2003;15(3):E10. doi:10.3171/foc.2003.15.3.10

6. Ambrossi GLG, McGirt MJ, Sciubba DM, et al. Recurrent lumbar disc herniation after single-level lumbar discectomy: incidence and health care cost analysis. Neurosurgery. 2009;65(3):574-578; discussion 578. doi:10.1227/01.NEU.0000350224.36213.F9

7. Cinotti G, Roysam GS, Eisenstein SM, Postacchini F. Ipsilateral recurrent lumbar disc herniation. A prospective, controlled study. $J$ Bone Joint Surg Br. 1998;80(5):825-832. doi:10.1302/0301620x.80b5.8540

8. Chuanli Z. Unique complications of percutaneous endoscopiclumbar discectomy and percutaneous endoscopicinterlaminar discectomy. Pain Phys. 2018;1(21;1):E105-E112. doi:10.36076/ppj.2018.2.E105 
9. Suk KS, Lee HM, Moon SH, Kim NH. Recurrent lumbar disc herniation: results of operative management. Spine. 2001;26 (6):672-676. doi:10.1097/00007632-200103150-00024

10. Kim K-T, Park S-W, Kim Y-B. Disc height and segmental motion as risk factors for recurrent lumbar disc herniation. Spine. 2009;34 (24):2674-2678. doi:10.1097/BRS.0b013e3181b4aaac

11. Dudli S, Fields AJ, Samartzis D, Karppinen J, Lotz JC. Pathobiology of modic changes. Eur Spine J. 2016;25(11):3723-3734. doi:10.1007/ s00586-016-4459-7

12. Fardon DF, Williams AL, Dohring EJ, Murtagh FR, Gabriel Rothman SL, Sze GK. Lumbar disc nomenclature: version 2.0. Spine J. 2014;14(11):2525-2545. doi:10.1016/j.spinee.2014.04.022

13. Castellvi AE, Goldstein LA, Chan DP. Lumbosacral transitional vertebrae and their relationship with lumbar extradural defects. Spine (Phila Pa 1976). 1984;9(5):493-495. doi:10.1097/00007632198407000-00014

14. Kang KK, Shen MS, Zhao W, Lurie JD, Razi AE. Retrolisthesis and lumbar disc herniation: a postoperative assessment of patient function. Spine J. 2013;13(4):367-372. doi:10.1016/j.spinee.2012. 10.017

15. Kim CH, Chung CK, Choi Y, et al. The selection of open or percutaneous endoscopic lumbar discectomy according to an age cut-off point: Nationwide Cohort Study. Spine (Phila Pa 1976). 2015;40(19): E1063-1070. doi:10.1097/BRS.0000000000001053

16. Wang H, Zhou Y, Li C, Liu J, Xiang L. Risk factors for failure of single-level percutaneous endoscopic lumbar discectomy. SPI. 2015;23(3):320-325. doi:10.3171/2014.10.SPINE1442

17. Kim MS, Park K-W, Hwang C, et al. Recurrence rate of lumbar disc herniation after open discectomy in active young men. Spine (Phila Pa 1976). 2009;34(1):24-29. doi:10.1097/BRS.0b013e31818f9116

18. Wu J, Zhang C, Lu K, Li C, Zhou Y. Percutaneous endoscopic lumbar reoperation for recurrent sciatica symptoms: a retrospective analysis of outcomes and prognostic factors in 94 patients. World Neurosurg. 2018;109:e761-e769. doi:10.1016/j.wneu.2017.10.077

19. He D, Li Z, Zhang T, Cheng X, Tian W. Prevalence of lumbar spondylolisthesis in middle-aged people in beijing community. Orthop Surg. 2021;13(1):202-206. doi:10.1111/os.12871

20. Grobler LJ, Robertson PA, Novotny JE, Pope MH. Etiology of spondylolisthesis. Assessment of the role played by lumbar facet joint morphology. Spine (Phila Pa 1976). 1993;18(1):80-91. doi:10.1097/00007632-199301000-00013
21. He X, Liang A, Gao W, et al. The relationship between concave angle of vertebral endplate and lumbar intervertebral disc degeneration. Spine. 2012;37(17):E1068-1073. doi:10.1097/BRS.0b013e318256 $40 \mathrm{eb}$

22. Xiao L, Ni C, Shi J, et al. Analysis of correlation between vertebral endplate change and lumbar disc degeneration. Med Sci Monit. 2017;23:4932-4938. doi:10.12659/msm.904315

23. Yeung AT, Tsou PM. Posterolateral endoscopic excision for lumbar disc herniation: surgical technique, outcome, and complications in 307 consecutive cases. Spine. 2002;27(7):722-731. doi:10.1097/ 00007632-200204010-00009

24. Kim JM, Lee SH, Ahn Y, Yoon DH, Lee CD, Lim ST. Recurrence after successful percutaneous endoscopic lumbar discectomy. Minim Invasive Neurosurg. 2007;50(2):82-85. doi:10.1055/s-2007-982504

25. Yao Y, Liu H, Zhang $\mathrm{H}$, et al. Risk factors for the recurrent herniation after microendoscopic discectomy. World Neurosurg. 2016;95: 451-455. doi:10.1016/j.wneu.2016.08.071

26. Karchevsky M, Schweitzer ME, Carrino JA, Zoga A, Montgomery D, Parker L. Reactive endplate marrow changes: a systematic morphologic and epidemiologic evaluation. Skeletal Radiol. 2005;34 (3):125-129. doi:10.1007/s00256-004-0886-3

27. Mok FPS, Samartzis D, Karppinen J, Fong DYT, Luk KDK, Cheung KMC. Modic changes of the lumbar spine: prevalence, risk factors, and association with disc degeneration and low back pain in a large-scale population-based cohort. Spine J. 2016;16(1):32-41. doi:10.1016/j.spinee.2015.09.060

28. Kirkaldy-Willis WH, Farfan HF. Instability of the lumbar spine. Clin Orthop Relat Res. 1982;(165):110-123.

29. Hasegawa K, Kitahara K, Hara T, Takano K, Shimoda H, Homma T. Evaluation of lumbar segmental instability in degenerative diseases by using a new intraoperative measurement system. J Neurosurg Spine. 2008;8(3):255-262. doi:10.3171/SPI/2008/8/3/255

30. Zhang B, Wang L, Wang H, Guo Q, Lu X, Chen D. Lumbosacral transitional vertebra: possible role in the pathogenesis of adolescent lumbar disc herniation. World Neurosurg. 2017;107:983-989. doi:10.1016/j.wneu.2017.07.095

31. Abbas J, Peled N, Hershkovitz I, Hamoud K. Is lumbosacral transitional vertebra associated with degenerative lumbar spinal stenosis? Biomed Res Int. 2019;2019:3871819. doi:10.1155/2019/3871819
Journal of Pain Research

\section{Publish your work in this journal}

The Journal of Pain Research is an international, peer reviewed, open access, online journal that welcomes laboratory and clinical findings in the fields of pain research and the prevention and management of pain. Original research, reviews, symposium reports, hypothesis formation and commentaries are all considered for publication. The manuscript

Submit your manuscript here: https://www.dovepress.com/journal-of-pain-research-journa management system is completely online and includes a very quick and fair peer-review system, which is all easy to use. Visit http:// www.dovepress.com/testimonials.php to read real quotes from published authors. 